Gut, 1988, 29, 385-389

Clinical trial

\title{
Treatment of ulcerative reflux oesophagitis with colloidal bismuth subcitrate in combination with cimetidine
}

\author{
M V BORKENT AND J A BEKER \\ From the Antoniushove Hospital, Leidschendam, The Netherlands
}

SUMmary Twenty patients took part in a controlled double blind study comparing the efficacy of colloidal bismuth and cimetidine $(800 \mathrm{mg}$ at night) with cimetidine alone in the treatment of ulcerative reflux oesophagitis. Colloidal bismuth $120 \mathrm{mg}$ was administered through an intraoesophageal tube four times a day. Cimetidine with colloidal bismuth gives significantly $(p<0 \cdot 001)$ better results than cimetidine alone. Of 10 patients treated with cimetidine and bismuth, seven had no endoscopic signs of oesophagitis after three weeks and three had grade I oesophagitis. Of 10 patients treated with cimetidine alone, one had grade I oesophagitis and three grade II oesophagitis after three weeks. The remaining six still had grade III oesophagitis. This study also shows that in nine of 10 patients reflux oesophagitis was accompanied by infection with campylobacter like organisms (CLO). After treatment the bacteria disappeared promptly in five patients receiving combination therapy and in two of four treated with cimetidine alone. The possible role of CLO in reflux oesophagitis is uncertain.

Gastro-oesophageal reflux is a quite common condition, usually accompanied by incompetence of the lower oesophageal sphincter. ${ }^{1-3}$ Oesophagitis develops in only about one half of patients with gastrooesophageal reflux. ${ }^{+}$

Reflux oesophagitis is usually treated with $\mathrm{H}_{2-}$ receptor antagonists, antacids in gel or drugs that promote gastric emptying together with postural and dietary recommendations. ${ }^{1}$ In some cases, however, the reflux oesophagitis does not respond to conventional therapy and admission to hospital is necessary. Persistent reflux oesophagitis remains a therapeutical challenge.

Colloidal bismuth subcitrate has been proved to be effective in peptic ulcer disease. It is known as a cytoprotective agent that stimulates the generation of mucosal prostaglandin $\mathrm{E}_{2}$ and retards the movement of hydrogen ions. ${ }^{56}$ Because of these properties colloidal bismuth was thought to be a useful therapeutic agent for ulcerative reflux oesophagitis. During the past three years 36 patients have been successfully treated with colloidal bismuth adminisAddress for correspondence: Dr J A Beker, Antoniushove Hospital, Burg Banninglaan 1, 2262 BA Leidschendam. The Netherlands.

Received for publication 4 September 1987. tered intraoesophageally; although a controlled double blind study was not carried out.

It was thought that campylobacter like organisms (CLO) might play a role in these results as bismuth is known to eradicate CLO. ${ }^{-9}$ In 1982 Marshall and Warren were able to isolate these spiral Gram negative organisms from gastric mucosa." "Since then CLO have been associated with biopsy proven gastritis as well as duodenal and gastric ulcers. Campylobacter like organisms are fairly rare in gastric biopsies without evidence of inflammation. $.7 \times 111-13$

The aim of the present study was to compare colloidal bismuth in combination with cimetidine and cimetidine alone for the treatment of reflux oesophagitis. Furthermore the proportion of patients with reflux oesophagitis and CLO was determined.

\section{Methods}

PATIENTS

Twenty patients (eight men, 12 women; mean age $69 \cdot 1$ years, (56-79)) with endoscopically and histologically proven grade III-IVa reflux oesophagitis ${ }^{14}$

(Table) were admitted to the trial. All patients had 
Table Classification of reflux oesophagitis: grades I to IV according to Savary and Miller

Grades
I $\begin{aligned} & \text { Non confluent erosions appearing as red spots or stripes, just } \\ & \text { proximal to the mucosal transition zone. } \\ & \text { Longitudinal, confluent, non-circumferential erosions ex- } \\ & \text { tending from the mucosal transition zone distalwards. } \\ & \text { II }\end{aligned}$ IIrcumferential confluent longitudinal erosions that blecd
III easily; no strictures.
IVa One or several ulcerations at the mucosal transition zone.
IVb Peptic stricture without indications of erosions or ulcer-
ations.

been previously treated with $\mathrm{H}_{2}$-receptor antagonists with or without antacids for at least three months. All patients were admitted to hospital during treatment. Patients with a grade IVb reflux oesophagitis, complications and Zollinger-Ellison disease, those receiving other drugs known to interfere with peptic ulcer disease, and those with cardiovascular, liver and renal diseases, malignancies and pregnancy were excluded from the study. After giving informed verbal consent, the patients were randomly allocated according to a double blind protocol to the group receiving cimetidine $(800 \mathrm{mg}$ at night) and colloidal bismuth $(120 \mathrm{mg}$ four times a day administered intraoesophageally) or to the group on cimetidine (800 mg at night) and a placebo (also administered intraoesophageally). An intraoesophageal tube was positioned just above the lesions, the localisation of which was established by endoscopy. The tube remained in place during the entire treatment period.

The colloidal bismuth was dissolved in $20 \mathrm{ml} 0.9 \%$ $\mathrm{NaCl}$ and subsequently administered within 20 minutes. After the infusion neither food nor liquids were allowed for 40 minutes. Otherwise there were no dietary restrictions.

Therapy was discontinued (1) when there was endoscopic evidence of a cure or (2) after three weeks. If after three weeks little or no improvement was seen, subsequent therapy depended upon the type of treatment given during the three week period. Those receiving cimetidine and a placebo were given colloidal bismuth for a maximum of three weeks. Those on combination therapy were put on a different therapeutic regimen (such as antacids in gel and high dose cimetidine).

Gastro-oesophageal reflux was confirmed by 24 hour intraoesophageal $\mathrm{pH}$ monitoring. ${ }^{15} \mathrm{~A}$ one channel digitrapper series 6000 recorder was used. The antimony $\mathrm{pH}$ electrode was positioned $5 \mathrm{~cm}$ above the gastro-oesophageal junction, the localisation of which was established by endoscopy. A pH measurement was recorded every four seconds for 24 hours. In all cases endoscopy was done every week by the same endoscopist. Biopsies were assessed histologically and microbiologically - that is, Gram stain and culture for CLO. Because CLO have been found to adhere to gastroscopes, ${ }^{16}$ the gastroscope and biopsy forceps were sterilised with a $2 \%$ solution of glutaraldehyde for 45 minutes and subsequently rinsed with tap water. Oesophageal biopsies were taken before the endoscope passed into the stomach in order to avoid contamination with possible antral CLO.

\section{MICROBIOLOGICAL INVESTIGATIONS}

One part of the specimen was stained by Gram's method. The remaining tissue was smeared onto two plates: one with a non-selective blood-agar base and one with a selective GC agar base containing hemin, isovitalex, vancomycin, colistin, nystatin and trimethoprim. The media were incubated after inoculation at $37^{\circ} \mathrm{C}$ in micro-aerophilic Campylobacter atmosphere in $10 \% \mathrm{CO}_{2}$ for a maximum of seven days. The CLO, when present, were then subcultured on a selective GC agar base and a non-selective blood agar base. Oxidase, catalase, and urease activities were determined for biotyping.

\section{Results}

Of the 10 patients treated with cimetidine and colloidal bismuth, six had no endoscopic signs of oesophagitis after two weeks and one was cured and

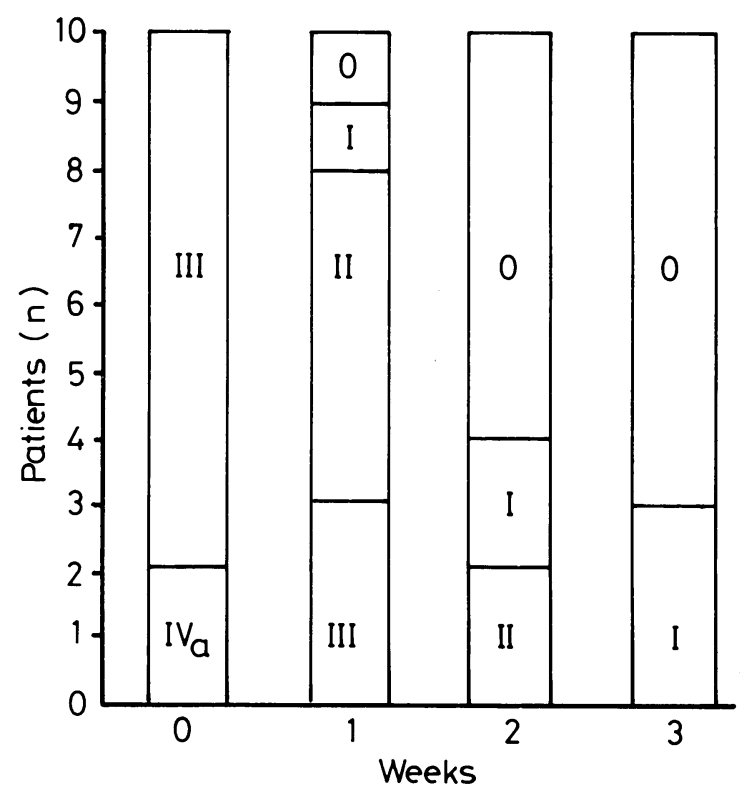

Fig. 1 Grade of oesophagitis in 10 patients treated with colloidal bismuth and cimetidine. 


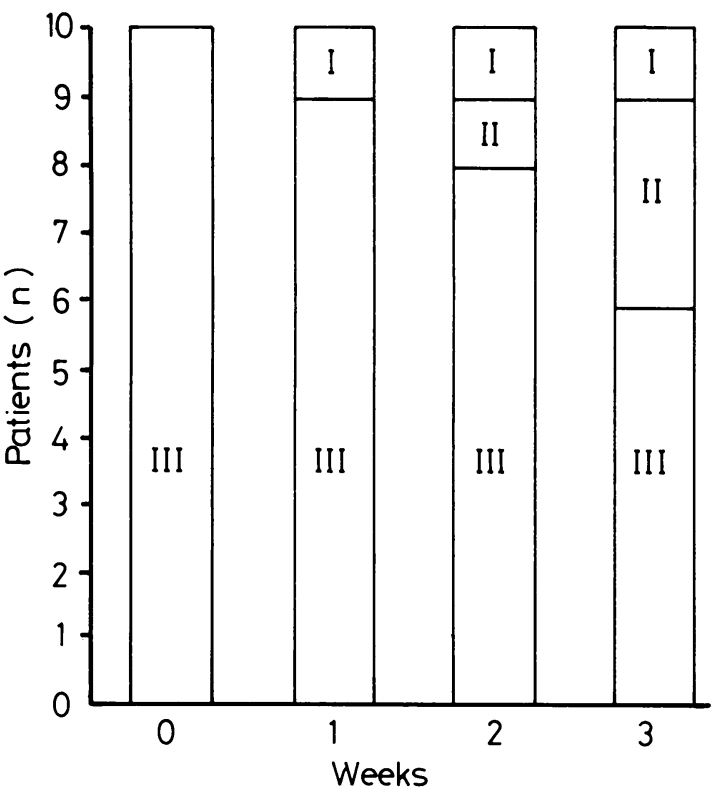

Fig. 2 Grade of oesophagitis in 10 patients treated with cimetidine.

three still had grade I reflux oesophagitis after three weeks (Fig. 1). Thus no additional therapy was necessary.

Of the 10 patients treated with cimetidine alone, one had grade I oesophagitis after one week and six showed no improvement and three still had grade II oesophagitis after three weeks (Fig. 2). The difference between the two groups was highly significant $\left(\chi^{2}=14 \cdot 61, \mathrm{df}=1, \mathrm{p}<0 \cdot 001\right)$.

Subsequently the nine patients with grade II-III oesophagitis after treatment with cimetidine alone also received colloidal bismuth. Three patients were cured after two weeks and three after three weeks; three patients still had a grade I oesophagitis.

Endoscopic grade $\mathrm{O}$ oesophagitis was established for seven patients who were treated initially with colloidal bismuth and cimetidine and six patients who received colloidal bismuth later. Three of these 13 patients also exhibited a histologically cured oesophagitis; the other 10 still showed signs of a mild oesophagitis - that is, minor to moderate increase in the number of polymorphonuclears and/or lymphocytes.

All cases of endoscopic grade III-IVa oesophagitis were confirmed histologically - that is, groups of polymorphonuclears throughout the specimen, numerous lymphocytes, and plasma cells and signs of ulceration.

Positive oesophageal cultures for CLO were found in nine cases, eight of which also had a positive antral culture. Whenever there was a positive antral culture there was endoscopic as well as microscopic evidence of a slight to moderate gastritis. Five of the nine patients were treated with colloidal bismuth; their CLO culture was negative within one week. Two of the four patients treated with cimetidine also remained positive. Campylobacter like organisms were found in squamous as well as cylindrical epithelium. An oesophageal ulcer in squamous epithelium with a CLO colony is shown in Fig. 3a, and b.

Three patients underwent a Belsey Mark IV reconstruction, after successful medical treatment. The others were discharged and have been taking colloidal bismuth tablets, dissolved in $5 \mathrm{ml}$ water, with and without cimetidine. The results will be evaluated after a one year follow up.

\section{Discussion}

The present study has shown that treatment of ulcerative reflux oesophagitis with colloidal bismuth and cimetidine gives better results than treatment with cimetidine alone. This conclusion is based on clinical, histological, and microbiological evaluation of 20 patients who took part in a double blind study.

In addition the study showed that in nine of 20 patients the oesophagitis is accompanied by an infection with CLO. This is a rather surprising finding because CLO are known to exhibit a preference for the antral mucosa. ${ }^{7-1217}$

In duodenal ulcers and duodenitis metaplasia of the antral epithelium has been suggested as a primary phenomenon. ${ }^{718}$ Metaplastic epithelium infected by CLO is likely to be more susceptible to damage by acid. The same theory might be applicable to ulcerative reflux oesophagitis.

The presence of antral gastritis with positive cultures for CLO in both antrum and oesophagus in patients with reflux oesophagitis might be more than coincidental. Impaired antral motility and delayed gastric emptying have been shown in patients with reflux oesophagitis, ${ }^{10} 210$ justifying the use of drugs that promote gastric emptying (such as metoclopramide). As CLO might play a pathogenetic role in antral gastritis, responsiveness to colloidal bismuth should be expected.

Obviously CLO are not present exclusively in the antrum and duodenum. They can also be found in inflamed oesophageal epithelium and might possibly be one of the causative factors in oesophagitis. Campylobacter like organisms might very well be a secondary invader of inflamed oesophageal tissue. It is remarkable that the bacteria disappeared promptly after initiation of colloidal bismuth therapy in all cases and even in two patients receiving cimetidine alone; in antral gastritis these bacteria exhibit greater 

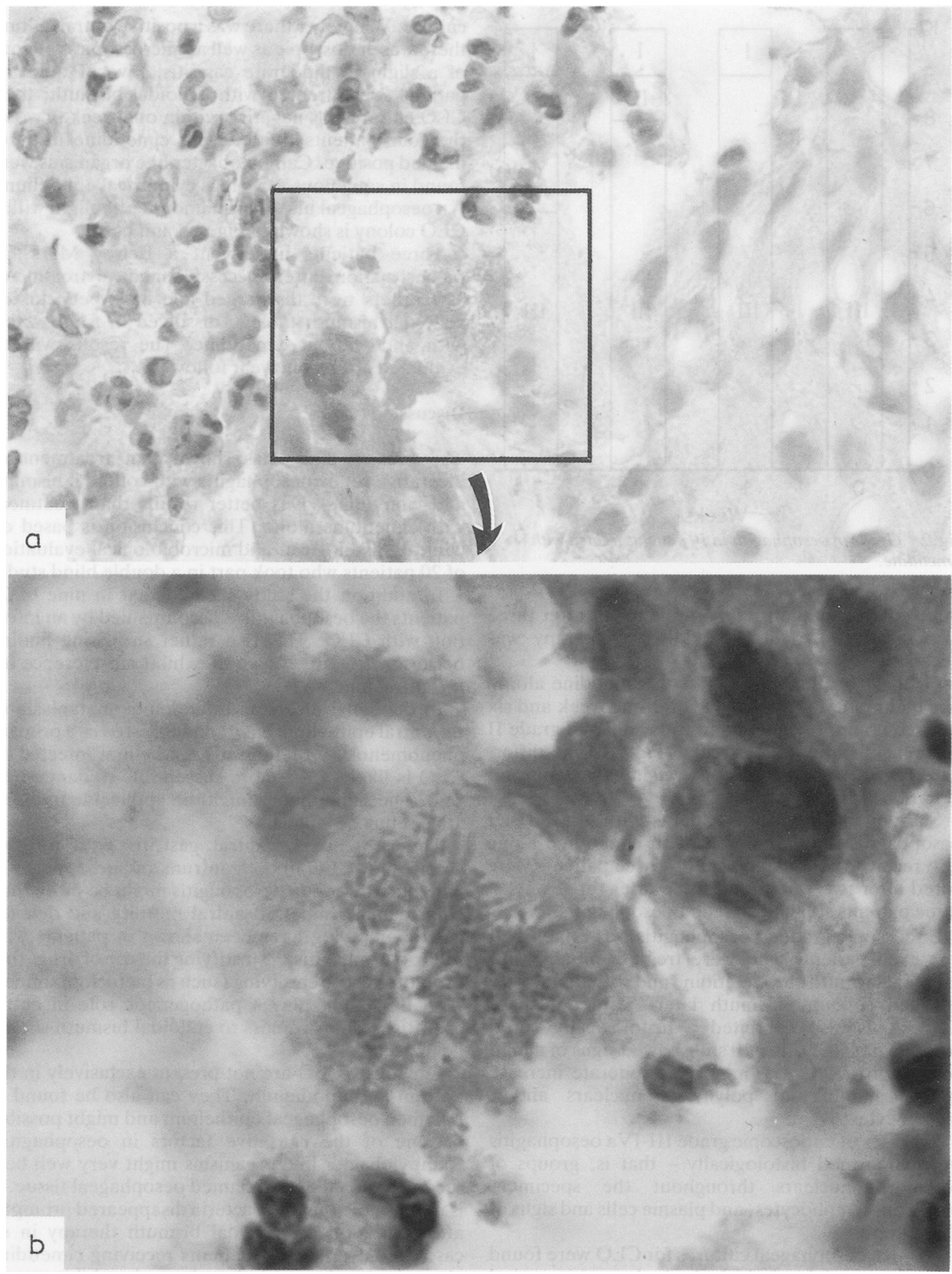

Fig. 3 (a) Oesophageal ulcer in squamous epithelium with a CLO colony (b) Detail. 
resistance to bismuth. Tytgat et al report a sensitivity to bismuth in $50 \%$ of their patients with antral gastritis and positive CLO cultures after eight weeks of therapy. ${ }^{57}$ At present the possible role of CLO in reflux oesophagitis remains highly hypothetical.

We would like to suggest the following indications for colloidal bismuth therapy in reflux oesophagitis (1) persistent reflux oesophagitis, (2) the need for rapid healing before surgical treatment and, perhaps (3) the presence of CLO.

We would like to thank Prof Dr R van Furth, Department of Infectious Diseases, Academic Hospital, Leiden, The Netherlands, for his valuable advice during the preparation of this manuscript.

\section{References}

1 Dodds WJ, Dent J, Hogan J, et al. Mechanisms of gastroesophageal reflux in patients with reflux esophagitis. N Engl J Med 1982; 307: 1547-52.

2 Kaye MD. Postprandial gastroesophageal reflux in healthy people. Gut 1977; 18: 709-12.

3 Demeester TR, Johnson LF, Joseph GJ, et al. Patterns of gastroesophageal reflux in health and disease. Ann Surg 1976; 184: 459-69.

4 Little AG, Demeester TR, Kirchnser PT, et al. Pathogenesis of esophagitis in patients with gastroesophageal reflux. Surgery 1980; 88: 101-7.

5 International De-Nol Symposium Milan 1985. Scand J Gastroenterol 1986; 21: suppl 122.

6 De-Nol Symposium at the 7th World Congress of Gastroenterology. Scand J Gastroenterol 1982; 17: suppl. 80.
7 Marshall B, McGechie D, Rogers P, et al. Pyloric campylobacter infection in gastroduodenal disease. Med $J$ Austr 1985; 142: 439-44.

8 Marshall BJ. Campylobacter pyloridis and gastritis. $J$ Infect Dis 1986; 153: 650-7.

9 McNulty CAM. The treatment of Campylobacter pyloridis in man. J Antimicrob Chemother 1987; 19: 281-4.

10 Warren JR. Unidentified curved bacilli in active chronic gastritis. Lancet 1983; i: 1273-5.

11 Marshall B. Unidentified curved bacilli in active chronic gastritis. Lancet 1983; i: 1273-5.

12 Andersen LP, Holck S, Povlsen CO, et al. Campylobacter pyloridis in peptic ulcer disease. Scand J Gastroenterol 1987; 22: 219-24.

13 Taylor DE, Hargreaves JA, Lai-King NG, et al. Isolation and characterization of Campylobacter pyloridis from gastric biopsies. Am J Clin Pathol 1987; 87: 49-54.

14 Savary M. L'osophage. Manuel et atlas d'endoscopie. Soleine: Gasman AG 1977.

15 Johnson LF, Demeester TR. Twenty four hour $\mathrm{pH}$ monitoring of the distal esophagus. Am J Gastroenterol 1974; 92: 325-32.

16 Fricker CR. Adherence of bacteria associated with active chronic gastritis to plastics used in the manufacture of fibreoptic endoscopes. Lancet 1984; i: 800.

17 Tytgat GNJ. De Campylobacter pyloridis story. Ned Tijdschr v Gen 1986; 130: 435-6.

18 Patrick WJR, Denham D, Forest APM. Mucous changes in the human duodenum. Gut 1974; 15: 767-76.

19 Behar J, Ramsby G. Gastric emptying and antral motility in patients with reflux esophagitis. Gastroenterology 1978; 74: 253.

20 Baldi F, Corinaldesi R, Ferrarini F, et al. Gastric secretion and emptying of liquids in reflux esophagitis. Dig Dis Sci 1981; 26: 886. 